\title{
PoETRY
}

\section{LMCCQE II}

Stickers march up their arms like a dozen bloodless cuts Defiant white flags not ready for surrender

"Your sticker please" Some need a prompt each time Lost in a transient fugue Facts playing hide-and-seek

The stickers are mere paper, black and white bar codes with years of study crammed between the parallel lines

\section{Anxious they watch} Sigh

as the gum grips the sheet, Seals their fate

A final spin and they're all used up The roulette drops the black ball The candidates cash in their chips A computer will calculate their fate

\section{Lauretta Pereles BA MD MSc Community physician Calgary, Alta.}

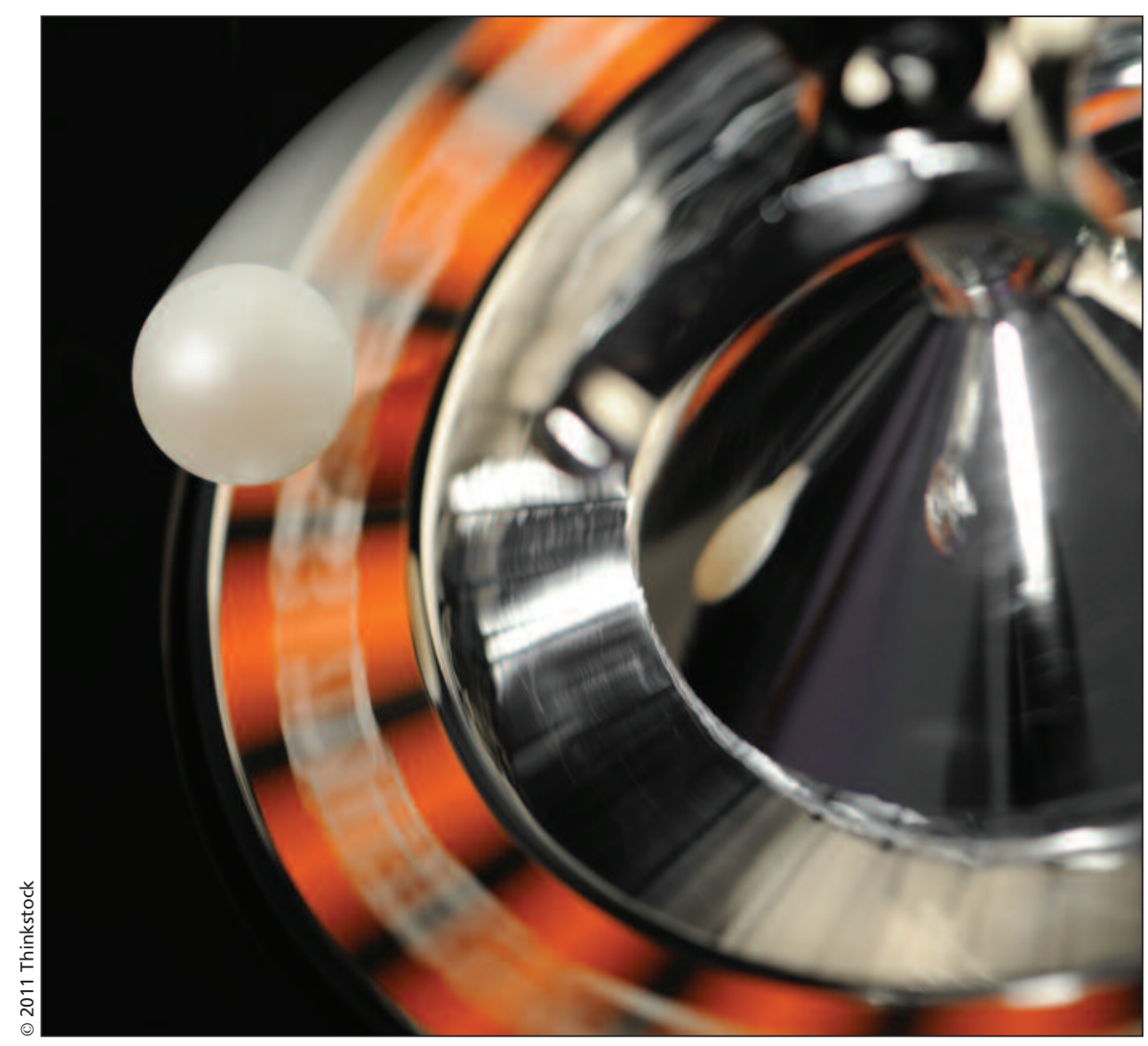

Editor's note: The LMCCQE II is the Licentiate of the Medical Council of Canada Qualifying Examination Part II, designed to assess the competence of candidates prior to entry into independent clinical practice.

CMAJ 2011. DOI:10.1503/cmaj.110536 